\title{
Synthesis of $\mathrm{WS}_{2}$ and $\mathrm{MoS}_{2}$ Fullerene-Like Nanoparticles from Solid Precursors
}

\author{
Inna Wiesel ${ }^{1}$, Hamutal Arbel ${ }^{1}$, Ana Albu-Yaron ${ }^{1}$, Ronit Popovitz-Biro ${ }^{2}$, Jeffrey M. Gordon ${ }^{3,4}$, Daniel Feuermann ${ }^{3}$, \\ and Reshef Tenne ${ }^{1}(\bowtie)$ \\ 'Department of Materials and Interfaces, Weizmann Institute of Science, Rehovot 76100, Israel \\ 2 Electron Microscopy Unit, Weizmann Institute of Science, Rehovot 76100, Israel \\ ${ }^{3}$ Department of Solar Energy and Environmental Physics, Jacob Blaustein Institutes for Desert Research, Ben-Gurion University of the \\ Negev, Beer Sheva Campus 84990, Israel \\ ${ }^{4}$ The Pearlstone Center for Aeronautical Engineering Studies, Department of Mechanical Engineering, Ben-Gurion University of the \\ Negev, Beer Sheva 84105, Israel \\ Received: 15 January 2009 / Revised: 22 February 2009 / Accepted: 23 February 2009 \\ CTsinghua University Press and Springer-Verlag 2009. This article is published with open access at Springerlink.com
}

\begin{abstract}
Inorganic fullerene-like $\mathrm{WS}_{2}$ and $\mathrm{MoS}_{2}$ nanoparticles have been synthesized using exclusively solid precursors, by reaction of the corresponding metal oxide nanopowder, sulfur and a hydrogen-releasing agent $\left(\mathrm{NaBH}_{4}\right.$ or $\mathrm{LiAlH}_{4}$ ), achieved either by conventional furnace heating up to $\sim 900{ }^{\circ} \mathrm{C}$ or by photothermal ablation at far higher temperatures driven by highly concentrated white light. In contrast to the established syntheses that require toxic and hazardous gases, working solely with solid precursors permits relatively safer reactor conditions conducive to industrial scale-up.
\end{abstract}

\section{KEYWORDS}

Nanoparticles, fullerene-like, synthesis, $\mathrm{WS}_{2}, \mathrm{MoS}_{2}$

\section{Introduction}

Inorganic fullerene-like (IF) nanoparticles and inorganic nanotubes (INT) comprise a large and expanding series of nanomaterials with closed-cage structures made of layered (2-D) as well as nonlayered (3-D) compounds. The first IF nanostructures and INT to be reported were prepared from layered $\mathrm{WS}_{2}$ and $\mathrm{MoS}_{2}[1,2]$, followed by their respective diselenides [3]. Subsequently, syntheses of IF nanoparticles and INT from many other layered compounds were developed, including transition metal disulfides (e.g., $\mathrm{NbS}_{2}[4,5], \mathrm{TaS}_{2}[4,6], \mathrm{TiS}_{2}[7]$, and $\mathrm{ReS}_{2}\left[8^{-10]}\right.$ ), transition metal oxides (e.g., $\mathrm{Cs}_{2} \mathrm{O}$ [11], $\mathrm{Tl}_{2} \mathrm{O}$ [12]) and halides (e.g., $\mathrm{CdI}_{2}$ [13]), and $\mathrm{BN}$ nanotubes [14]. INT were also prepared from quasiisotropic compounds (e.g., $\mathrm{MgO}$ [15]) and from spinels (e.g., $\mathrm{ZnAl}_{2} \mathrm{O}_{4}$ [16]) by using the Kirkendall principle. For a comprehensive review of the field and the different synthetic routes, the reader is referred to a number of review articles [17-19].

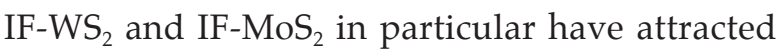
considerable interest due to their wide range of promising applications. It was found, for example,

Address correspondence to reshef.tenne@weizmann.ac.il 
that such nanoparticles can serve as superior solid lubricants [20] and can improve the mechanical properties of various nanocomposites [21, 22]. The synthetic methods employed to produce IF nanoparticles and INT can be divided roughly into two categories: (1) far from equilibrium processes such as laser ablation [23], arc discharge [14] and electron beam irradiation [3, 24, 25] and (2) chemical methods like chemical vapor transport [26] which operate in a regime closer to equilibrium and generate higher yields [27, 28]. A successful scalingup for the synthesis of INT-WS ${ }_{2}$ with a fluidized bed reactor was recently reported [29].

One of the major problems in scaling up the IF syntheses to industrial levels is the use of toxic and hazardous gases such as $\mathrm{H}_{2} \mathrm{~S}$ and $\mathrm{H}_{2}$ which are difficult to handle and store. Although a few chemical strategies have been reported to address this issue [30, 31], in general they are not compatible with fluidized bed reactors and therefore are difficult to scale up. In the present work, these gases have been replaced by solid precursors, i.e., alkali metal tetrahydroborates $\left((\mathrm{Na}, \mathrm{Li}) \mathrm{BH}_{4}\right)$, tetrahydroaluminates $\left((\mathrm{Na}, \mathrm{Li}) \mathrm{AlH}_{4}\right)$, and elemental sulfur. The rationale is that the hydrides become unstable at elevated temperatures and release hydrogen which reacts with the sulfur vapor to provide the required reducing atmosphere. The results reported here offer preliminary evidence that current industrial procedures for the production of IF-MS ${ }_{2}(\mathrm{M}=\mathrm{W}, \mathrm{Mo})$ and INT could be replaced by a more benign process.

All the reactions in the present study were performed in sealed quartz ampoules. The limitation of a closed, nominally static reaction environment led to contamination of the final product with residues from the solid metal hydride which was oxidized during the reaction. Frequently, the synthesized nanoparticles were covered by an amorphous film (believed to be residues of the oxidized material) which made it difficult to obtain focused microscope images. An improved design for future reactors could physically separate the hydrogen-generating moiety from the other precursors (sulfur and metal oxide), although current fluidized bed reactors would have to be altered in order to replace the gases currently used with a solid reducing agent.
Two distinct strategies were used independently to drive the high-temperature reaction: (1) a standard thermal furnace and (2) photothermal ablation by concentrated ultra-intense white light. The reaction in the furnace could be maintained at a controlled temperature up to a maximum of $900{ }^{\circ} \mathrm{C}$, with uniform heating of the reactor ampoule for relatively long periods under near equilibrium conditions.

In contrast, the photothermal ablation experiments, performed separately with highly concentrated sunlight using fiber-optic concentrators reported previously [32,33] (see Fig. 1(a)), and with the optically reconstituted plasma source of ultrabright xenon short-arc discharge lamps [34] (see Fig. 1(b)) create a strongly non-equilibrium environment characterized by sharp radiative flux and temperature gradients. Peak temperatures appear to be in excess of $1700{ }^{\circ} \mathrm{C}$. This observation is supported by the fact that in related experiments, pure quartz was shown to melt and transform into nanobeads and nanowires [33].

Reaction times are markedly shorter with focused light heating, compared to the furnace experiments, albeit with limited control of reaction conditions. Furthermore, at these elevated temperatures the gas pressure of the tungsten oxide is non-negligible, which leads to vaporization of the nanoparticle

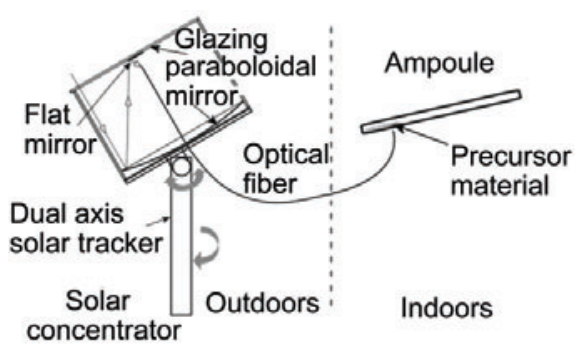

(a)

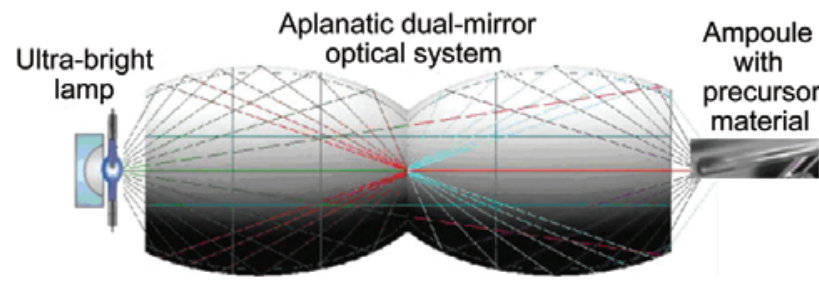

(b)

Figure 1 Schematics of the photothermal ablation experiments performed with (a) sunlight concentrated into optical fibers and delivered indoors onto the reactor, and (b) xenon short-arc discharge lamps where the lamp's ultra-bright radiant plasma is optically reconstituted on the reactor 
core (vide infra). Presently, the main stimulus for the photothermal ablation experiments is their proven potential to produce unique nanostructures [32, 33], though with low yields.

The conversion of both $\mathrm{WO}_{3}$ and $\mathrm{MoO}_{3}$ nanoparticles into their respective IF-MS $(\mathrm{M}=\mathrm{Mo}$, $\mathrm{W})$ has been extensively investigated [35-37]. The reaction path can be divided into two distinguishable stages. The first step is a surface reaction that lasts ca. $1 \mathrm{~s}$, during which the surface of the oxide nanoparticle is converted into 1-2 closed monolayers of the metal disulfide. The oxide core is partially reduced during or somewhat after the first step due to the fast inward diffusion of hydrogen. The second step consists of a slow diffusion of sulfur atoms from the vapor phase through the already existing closed sulfide layers into the oxide core of the nanoparticle. The exchanged oxygen atoms diffuse outwards from the oxide core onto the nanoparticle surface. This slow diffusion-controlled reaction produces IF nanoparticles with highly crystalline order and lasts about $60 \mathrm{~min}$ for $100 \mathrm{~nm}$ nanoparticles produced at $850^{\circ} \mathrm{C}$.

At the far higher temperatures created in the photothermal ablation reactor, the reaction mechanism can be altered. Although the rates of diffusionlimited chemical processes quicken, a few additional processes (e.g., vaporization of the oxide core) can occur. Since atomic diffusion rates vary exponentially with temperature, ultra-high reactor temperatures can dramatically shorten the time required for completion of the reaction. Conversely, the vapor pressure of the metal oxide in the core of the nanoparticle increases, leading to partial evaporation of the oxide core [38] and, as shown below, also to the rupture of the outer closed metal sulfide layers.

Furthermore, annealing of the defects and dislocations in the IF closed structure is a slow diffusion-controlled process, leading in general to more faceted IF nanostructures with higher crystalline order [5]. These considerations were important in motivating and planning the photothermal ablation experiments, in part because annealing of the reaction product is expected to lead to improved crystallinity of the product.

\section{Experimental}

\subsection{Preparation of the reacting mixture}

Several reactant mixtures were prepared, with different molar ratios of ingredients. For each molar ratio, a mixture of metal oxide powder and sulfur was prepared in advance. The components were mixed and thoroughly ground with mortar and pestle to obtain a fine and uniform powder. The $\mathrm{WO}_{3}$ precursor powder consisted mostly of nanoparticles below $200 \mathrm{~nm}$ in size. The $\mathrm{MoO}_{3}$ precursor powder particles were as large as a few microns, but because $\mathrm{MoO}_{3}$ powder evaporates at temperatures above $\sim 650{ }^{\circ} \mathrm{C}$ [35], the particle size is irrelevant for the synthesis of IF-MoS ${ }_{2}$. Rather, the size of the product nanoparticles is determined by the rate of oxide reduction within the reactor. The solid hydrogenreleasing agent $\left(\mathrm{LiAlH}_{4}\right.$ or $\left.\mathrm{NaBH}_{4}\right)$ was added to the mixture shortly before sealing the ampoule, which in some cases was performed in a glove box so as to minimize water uptake. For the glove-box preparation, the ampoule was sealed in an argon atmosphere using a Rotaflo valve inside the glovebox and the argon gas was subsequently evacuated.

The ampoules were first evacuated to $10^{-4}$ mbar. In some cases, after evacuation the ampoule was flushed several times with helium and then sealed under helium at a pressure of 0.5 mbar. In some of the solar ablation experiments, a small amount of carbon powder was added to the mixture, in order to increase the light absorption and hence temperature of the reacting mixture. In addition, carbon serves as a supplementary reducing agent at elevated temperatures [39].

\subsection{Furnace experiments}

Sealed quartz ampoules $12 \mathrm{~mm}$ in diameter and $100 \mathrm{~mm}$ in length were positioned vertically in a furnace which had been preheated to the desired temperature. The temperatures varied between 600 and $900{ }^{\circ} \mathrm{C}$. Reaction time was varied from 10 to 120 min, after which the ampoule was removed from the heated furnace and allowed to cool to room temperature. 


\subsection{Solar and lamp ablation experiments}

The reactions were carried out in $8 \mathrm{~mm}$ diameter, $100 \mathrm{~mm}$ long, sealed quartz ampoules. Pyrometrically measured radiative power delivery onto the reactor ranged from 10 to $25 \mathrm{~W}$ over a target area of a few $\mathrm{mm}^{2}$. Exposure time was varied from 1 to $15 \mathrm{~min}$.

\subsection{The chemical reactions}

In the original reaction [35-37] the metal oxides react with $\mathrm{H}_{2} \mathrm{~S}$ and $\mathrm{H}_{2}$ according to the following schematic equation:

$\mathrm{MO}_{3}+2 \mathrm{H}_{2} \mathrm{~S}+\mathrm{H}_{2} \rightarrow \mathrm{MS}_{2}+3 \mathrm{H}_{2} \mathrm{O}(\mathrm{M}=\mathrm{Mo}, \mathrm{W})$

In our reactions, the hydrides start to decompose and release hydrogen at relatively low temperatures — $150{ }^{\circ} \mathrm{C}$ for $\mathrm{LiAlH}_{4}$, and $300{ }^{\circ} \mathrm{C}$ for $\mathrm{NaBH}_{4}$. When the temperature was further increased, the sulfur volatilized at $\sim 400{ }^{\circ} \mathrm{C}$ and reacted with the hydrogen to form $\mathrm{H}_{2} \mathrm{~S}$ in situ. At this stage, the metal oxide particles are already partially reduced by the hydrogen present in excess and readily react with hydrogen sulfide. The overall reaction can be described as

$2 \mathrm{MO}_{3}+3 \mathrm{NaBH}_{4}+4 \mathrm{~S} \rightarrow 2 \mathrm{MS}_{2}+3 \mathrm{NaBO}_{2}+6 \mathrm{H}_{2}$

$(\mathrm{M}=\mathrm{Mo}, \mathrm{W})$

Note that $\mathrm{Na}$ can be exchanged by $\mathrm{Li}$, and $\mathrm{B}$ can be exchanged by Al.

\subsection{Sample preparation and analysis}

The product, obtained in the form of black agglomerated powder, was analyzed mainly by means of various electron microscopy techniques: (1) transmission electron microscope (Philips CM120 TEM) operating at $120 \mathrm{kV}$, equipped with an EDS detector (EDAX-Phoenix Microanalyzer), and (2) high-resolution TEM (HRTEM) with a field emission gun (FEI Technai F30-UT) operating at $300 \mathrm{kV}$, equipped with a parallel electron energy loss (EELS) spectrometer that included a Gatan imaging filter.

Powders with a large excess of sulfur were sonicated in ethanol. In some cases, samples were further washed in ethanol, filtered, dried, and the procedure repeated several times. All powders analyzed by electron microscopy were also first sonicated in ethanol, and then placed onto carbon/ collodion/ $\mathrm{Cu}$ grids (for TEM) or on lacey carbon/ $\mathrm{Cu}$ grids (for HRTEM and EELS).
Complementary analyses were carried out by powder X-ray diffraction (XRD).

\section{Results and discussion}

A few tens of experiments were carried out with both the molybdenum and tungsten compounds. The yields of IF nanoparticles varied, with furnacedriven experiments exhibiting substantially higher yields than those obtained by photothermal ablation (vide infra). The crystalline quality of the products was consistently inferior to those achieved in earlier alternative chemical syntheses [35-37]. However, IF-MoS ${ }_{2}$ nanoparticles were produced only in the focused-light experiments (and not in the furnace).

\subsection{Furnace experiments}

Figure 2 shows a typical assortment of IF- $\mathrm{WS}_{2}$ nanoparticles obtained in the furnace-driven experiments. The product appears to be nonuniform, with part of the nanoparticles filled with oxide (Fig. 2(a)) while others exhibiting a hollow core (Fig. 2(b)). The size and shape of the synthesized nanoparticles are reminiscent of the precursor oxide nanoparticles. The final morphology of the IF nanoparticles is also determined by the strain relief mechanism of the structure, which is influenced by the reaction temperature, number of $\mathrm{MS}_{2}$ layers, etc. [5]. The nanoparticles appear to be agglomerated (Fig. 2(c)) which hinders obtaining a high-quality image of the individual nanoparticles. The defects and imperfections from which the crystallinity of the nanoparticles suffers are readily apparent.

The yield of the IF-WS $\mathrm{W}_{2}$ nanoparticles peaked at ca. $50 \%$ for reaction times of $\sim 15-20 \mathrm{~min}$. Longer reaction times resulted in the progressive conversion of the IF nanoparticles into platelets, whereas shorter reaction times produced partially reacted oxide particles covered with 1-3 layers of sulfide. Pure IF$\mathrm{WS}_{2}$ nanoparticles are not readily transformed into platelets unless a suitable catalyst is present. The decrease in IF-WS ${ }_{2}$ yield and increase in the quantity of platelets at reaction times exceeding ca. 20 min are probably a consequence of the catalytic action of the metal hydrides in the reaction mixture.

Although reduction of the tungsten oxide core can 


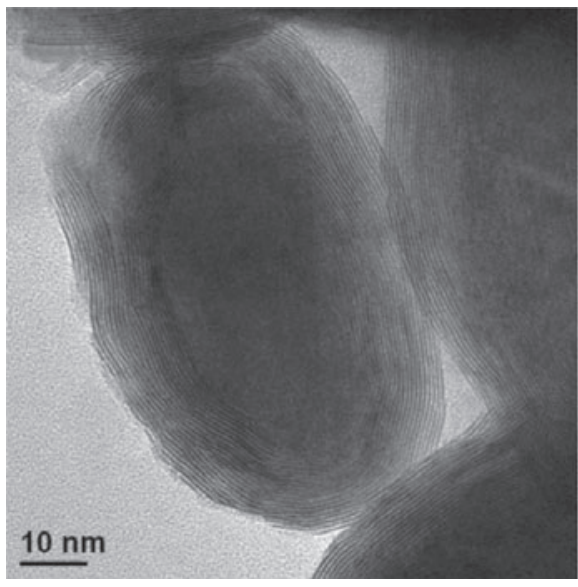

(a)

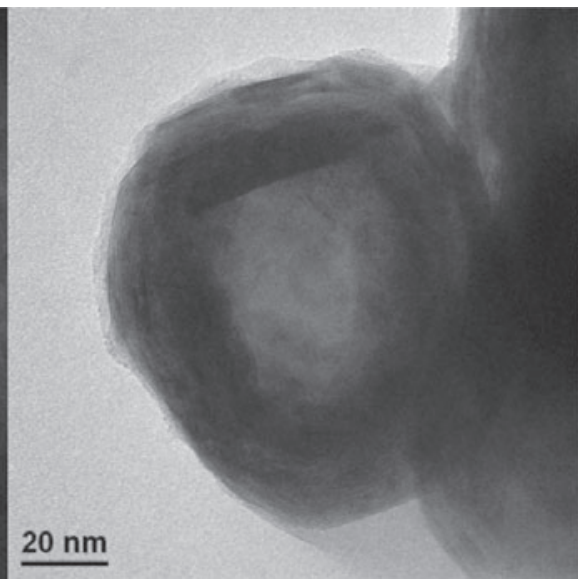

(b)

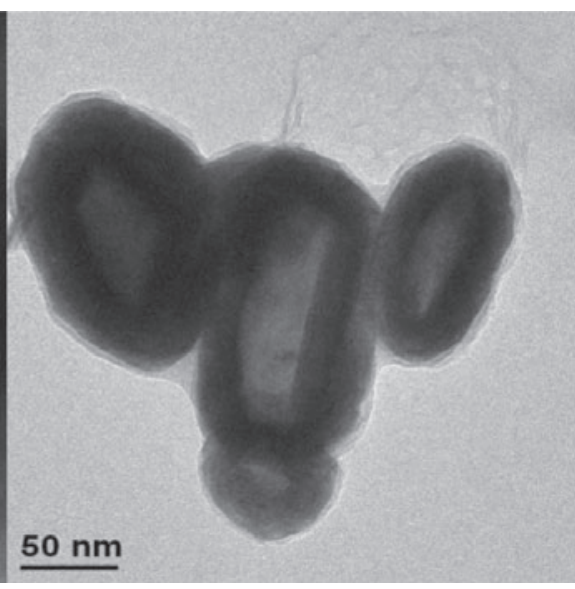

(c)

Figure 2 TEM images of representative IF-WS $\mathrm{WS}_{2}$ nanoparticles generated in furnace experiments: (a) nanoparticle with a $\mathrm{WO}_{3}$ core, from a reaction with $\mathrm{LiAlH}_{4}$; (b) hollow-core nanoparticle, from a reaction with $\mathrm{LiAlH}_{4}$; (c) group of attached nanoparticles, from a reaction with $\mathrm{NaBH}_{4}$

proceed totally to pure tungsten, it often terminates in $\mathrm{WO}_{2}$ which is not readily converted to the sulfide within the IF nanoparticle core [37]. It is therefore suggested that the metal oxide nanoparticles were only mildly reduced to $\mathrm{WO}_{3-x}$ which was fully converted into the sulfide. Indeed, in accordance with previous studies [37], the size and shape of the IF-WS ${ }_{2}$ nanoparticles are reminiscent of these oxide nanoparticles. A few short $\mathrm{WS}_{2}$ nanotubes were also observed (Fig. 3).

EDS analysis of the product revealed only tungsten and sulfur atoms, but in a ratio well below 1:2 (not unexpected since EDS generally underestimates the presence of sulfur, which reinforces the significance of TEM and electron diffraction analyses). In addition, the products of the reaction of the ternary

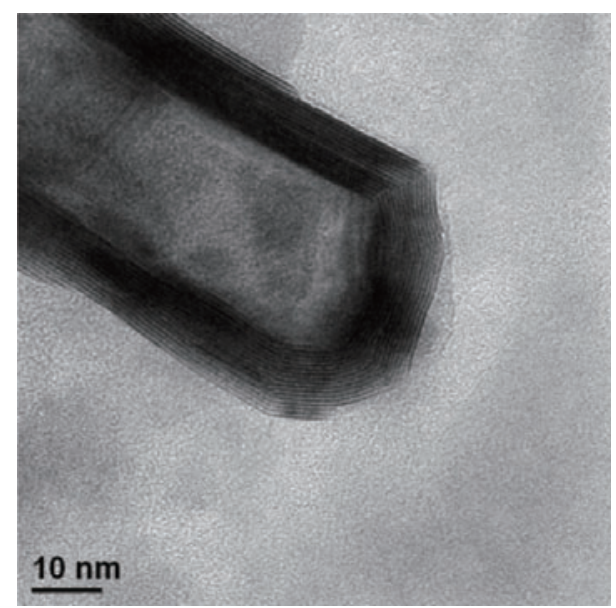

Figure 3 TEM image of the tip of a short $\mathrm{WS}_{2}$ nanotube, from a reaction with $\mathrm{LiAlH}_{4}$ in the furnace hydride agent are also observed. In particular, for $\mathrm{NaBH}_{4}$, sodium and oxygen residues are evident in both the IF and INT products (the boron peak is below the detectable energy range). Avoiding crosscontamination of this type, by separating the metal hydride from the reaction mixture, is a goal for future experiments. EELS/HRTEM analysis further confirmed that the nanoparticles consisted purely of sulfur and tungsten. The remains of the $\mathrm{LiAlH}_{4}$ were manifested as aluminum and oxygen peaks, distributed non-uniformly throughout the product.

\subsection{Photothermal solar and lamp ablation experiments}

In contrast to the furnace experiments, the intense irradiation is highly localized, with a concomitant steep temperature (and effective annealing environment) gradient in the ampoule. Yields of IF$\mathrm{WS}_{2}$ nanoparticles were low: the highest yield of ca. $5 \%$ for IF-WS $\mathrm{W}_{2}$ nanoparticles was obtained for a reaction time of $1 \mathrm{~min}$. The short reaction (and hence short annealing) times appear to result in a greater degree of defects and irregularities in the nanoparticles produced relative to the furnace experiments. Reaction times less than $\sim 1 \mathrm{~min}$ resulted in partially reacted oxide particles covered with one to several layers of sulfide (similar to the short-reaction behavior observed in the furnace experiments).

Figure 4 shows representative product IF$\mathrm{WS}_{2}$ nanoparticles, comprising fewer $\mathrm{WS}_{2}$ layers 


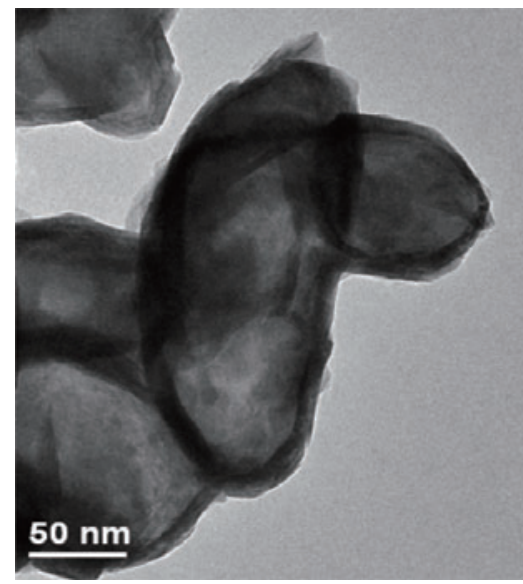

(a)

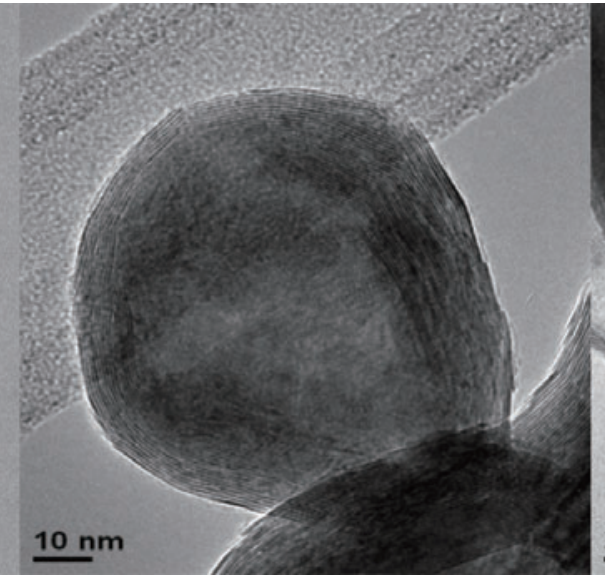

(b)

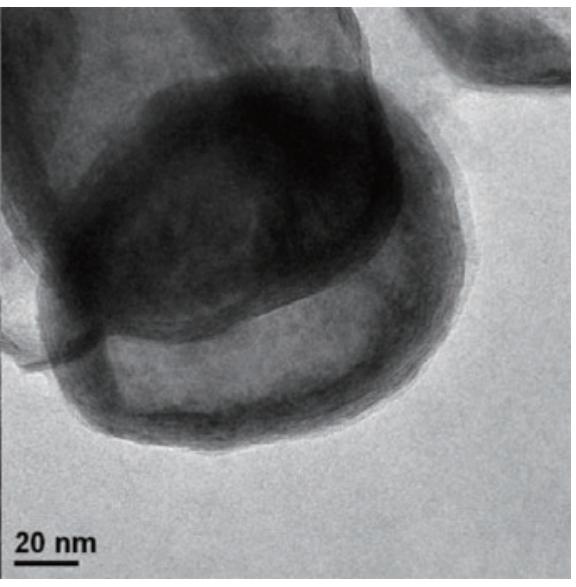

(c)

Figure 4 TEM images of representative groups of IF-WS 2 nanoparticles generated by photothermal ablation: (a) by solar ablation, from reaction with $\mathrm{NaBH}_{4}$; (b) by lamp ablation, from reaction with $\mathrm{LiAlH}_{4}$; (c) by lamp ablation, from reaction with $\mathrm{NaBH}_{4}$

compared to products from the furnace experiments. Consistent with previous studies, the shape and size of the nanoparticles reflect those of the oxide precursor. $\mathrm{WO}_{3}$ becomes volatile at temperatures above $1200{ }^{\circ} \mathrm{C}$, but the reduced $\mathrm{WO}_{3-x}$ evaporates only at higher temperatures; these elevated temperatures also enhance both the sulfidization process and the reduction of the oxide core. The competition between these three processes (evaporation of the oxide, its reduction, and sulfidization) determine the number of closed layers of the IF-WS ${ }_{2}$ nanoparticles and the fidelity of its crystalline structure. It is also likely that the abundance of defects leads to faster diffusion of sulfur from the outside and towards the core of the nanoparticles.
Some samples exhibited partial damage to the nanoparticles, as if a pressure increase inside the core led to rupture of the $\mathrm{WS}_{2}$ layers - attributable to ultra-high local reactor temperatures (see Fig. 5). In fact, the peak temperature $\left(\sim 1700{ }^{\circ} \mathrm{C}\right)$ in a small region inside the reactor exceeds the decomposition temperature of all forms of the desired products (crystalline, IF or otherwise), which would destroy any IF nanostructures that form and remain in that immediate vicinity rather than in the proximate annealing environment. These competing effects may partially explain the relatively low yields for the photothermal ablation technique with static reactants, in contrast, say, to fluidized bed configurations (delegated to future investigations). Furthermore, the

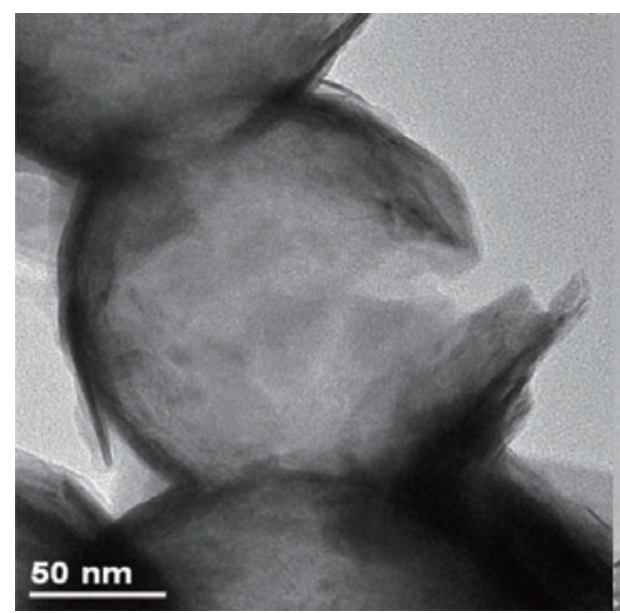

(a)

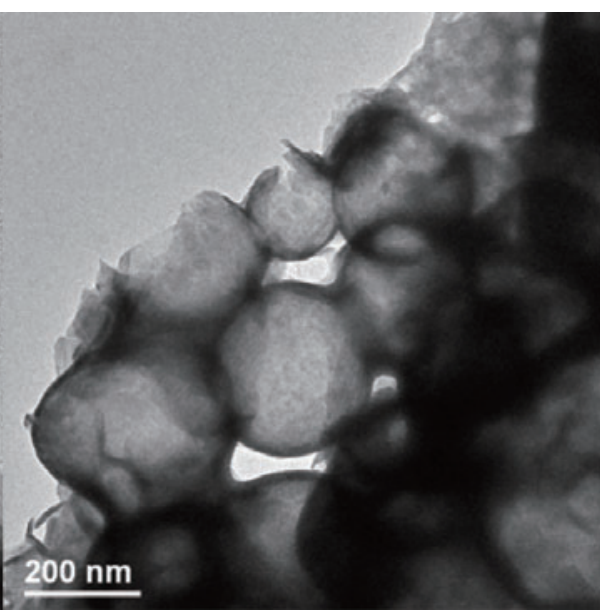

(b)

Figure 5 TEM images of ruptured IF-WS $\mathrm{S}_{2}$ nanoparticles produced during solar ablation, from reaction with $\mathrm{NaBH}_{4}$ 


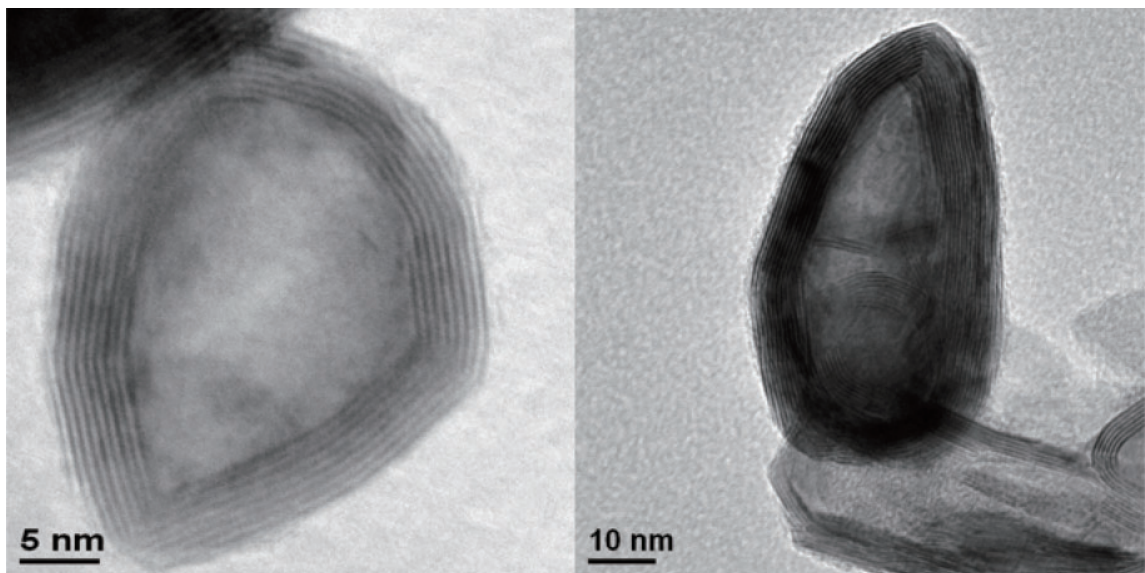

(a)

(b)

Figure 6 TEM micrographs of two typical IF-MoS nanoparticles produced by solar ablation, from reaction with $\mathrm{NaBH}_{4}$

reduction in IF yields at relatively long reaction time may also stem in part from the catalytic effect of the metal hydrides in converting IF-WS ${ }_{2}$ and IF-MoS into platelets (analogous to the trend observed in the furnace experiments).

Figure 6 shows representative IF- $\mathrm{MoS}_{2}$ nanoparticles generated in photothermal ablation experiments (IF- $\mathrm{MoS}_{2}$ was not detected in any of the furnace experiments), albeit at low yields $(<1 \%)$. The observed particles are small $(\sim 30-70 \mathrm{~nm}$ in linear dimension) due to the formation mechanism of IF$\mathrm{MoS}_{2}$ being somewhat different from that of IF-WS [35]. The reaction mechanism for the synthesis of IF-MoS ${ }_{2}$ is more complex than that of the tungsten analogue [35]. The size of the nanoparticles is determined by the rate of $\mathrm{MoO}_{3}$ evaporation and its reduction by the hot hydrogen gas, which can be controlled by a proper temperature gradient. Since the ablation process is rapid and the temperature gradients are high, the nanoparticle size and shape control in the experiments are limited at the present time.

\section{Conclusions}

The synthesis of fullerene-like nanoparticles of $\mathrm{WS}_{2}$ and $\mathrm{MoS}_{2}$ using solely solid precursors has been demonstrated. The reducing atmosphere is provided by metal hydrides, e.g., $\mathrm{NaBH}_{4}$, which, upon mild heating, release hydrogen. The reaction was carried out by two distinct methods: (1) resistive furnace heating $\left(600-900{ }^{\circ} \mathrm{C}\right)$ that creates near-equilibrium conditions, and (2) photothermal ablation with highly concentrated light from solar radiation or ultra-bright lamps $\left(\sim 1700{ }^{\circ} \mathrm{C}\right.$, for short periods of time $)$ that creates a non-equilibrium environment with large flux and temperature gradients.

Analysis of the IF nanostructures reveals somewhat different reaction mechanisms for the two strategies and noticeably higher yields (up to 50\%) in the furnace experiments, with extensive defects in essentially all of the synthesized nanoparticles. Molybdenum disulfide IF nanoparticles were only produced with the photothermal ablation technique.

The primary focus of this investigation is to communicate the formulation and experimental realization of a new scheme for synthesizing fullerene-like $\mathrm{WS}_{2}$ and $\mathrm{MoS}_{2}$ nanostructures entirely with solid precursors that release the gaseous reducing agents required for the reactions, thereby obviating the need for the toxic and dangerous precursor gases currently used in syntheses of these materials. The preliminary experimental results reported here indicate that considerable further research is required to both unequivocally decipher the reaction mechanism, as well as optimize reactor design.

\section{Acknowledgements}

This research was supported by the Gurwin Fund, the Horowitz Foundation, and the Harold Perlman 
Foundation. The solar and lamp ablation experiments were supported by the Israeli Ministry of Science and Technology (inter-institutional grant 3-3441). The electron microscopy studies were carried out at the Moskovitz Center for Nano and Bio Imaging. R. T. holds the Drake Family Chair in Nanotechnology and is the Director of the Helen and Martin Kimmel Center for Nanoscale Science.

\section{References}

[1] Tenne, R.; Margulis, L.; Genut, M.; Hodes, G. Polyhedral and cylindrical structures of tungsten disulfide. Nature 1992, 360, 444-446.

[2] Margulis, L.; Salitra, G.; Tenne, R.; Talianker, M. Nested fullerene-like structures. Nature 1993, 365, 113-114.

[3] Hershfinkel, M.; Gheber, L. A.; Volterra, V.; Hutchison, J. L.; Margulis, L.; Tenne, R. Nested polyhedra of $\mathrm{MX}_{2}$ $(\mathrm{M}=\mathrm{W}, \mathrm{Mo} ; \mathrm{X}=\mathrm{S}, \mathrm{Se})$ probed by high-resolution electronmicroscopy and scanning-tunneling-microscopy. J. Am. Chem. Soc. 1994, 116, 1914-1917.

[4] Nath, M.; Rao, C. N. R. New metal disulfide nanotubes. J. Am. Chem. Soc. 2001, 123, 4841-4842.

[5] Schuffenhauer, C.; Popovitz-Biro, R.; Tenne, R. Synthesis of $\mathrm{NbS}_{2}$ nanoparticles with (nested) fullerene-like structure (IF). J. Mater. Chem. 2002, 12, 1587-1591.

[6] Schuffenhauer, C.; Parkinson, B. A.; Jin-Phillipp, N. Y.; Joly-Pottuz, L.; Martin, J. M.; Popovitz-Biro, R.; Tenne, R. Synthesis of fullerene-like tantalum disulfide nanoparticles by a gas-phase reaction and laser ablation. Small 2005, 1, 1100-1109.

[7] Margolin, A.; Popovitz-Biro, R.; Albu-Yaron, A.; Rapoport, L.; Tenne, R. Inorganic fullerene-like nanoparticles of $\mathrm{TiS}_{2}$. Chem. Phys. Lett. 2005, 411, 162-166.

[8] Coleman, K. S.; Sloan, J.; Hanson, N. A.; Brown, G.; Clancy, G. P.; Terrones, M.; Terrones, H.; Green, M. L. H. The formation of $\mathrm{ReS}_{2}$ inorganic fullerene-like structures containing $\mathrm{Re}_{4}$ parallelogram units and metal-metal bonds. J. Am. Chem. Soc. 2002, 124, 11580-11581.

[9] Brorson, M.; Hansen, T. W.; Jacobsen, C. J. H. Rhenium(IV) sulfide nanotubes. J. Am. Chem. Soc. 2002, 124, 11582-11583.

[10] Yella, A.; Therese, H. A.; Zink, N.; Panthoefer, M.; Tremel, W. Large scale MOCVD synthesis of hollow ReS nanoparticles with nested fullerene-like structure. Chem. Mater. 2008, 20, 3587-3593.
[11] Albu-Yaron, A.; Arad, T.; Popovitz-Biro, R.; Bar-Sadan, M.; Prior, Y.; Jansen, M.; Tenne, R. Preparation and structural characterization of stable $\mathrm{Cs}_{2} \mathrm{O}$ closed-cage structures. Angew. Chem. Int. Ed. 2005, 44, 4169-4172.

[12] Avivi, S.; Mastai, Y.; Gedanken, A. A new fullerene-like inorganic compound fabricated by the sonolysis of an aqueous solution of $\mathrm{TICl}_{3}$. J. Am. Chem. Soc. 2000, 122, 4331-4334.

[13] Sallacan, N.; Popovitz-Biro, R.; Tenne, R. Nanoparticles of $\mathrm{Cdl}_{2}$ with closed cage structures obtained via electronbeam irradiation. Solid-State Sci. 2003, 5, 905-908.

[14] Chopra, N. G.; Luyken, R. J.; Cherrey, K.; Crespi, V. H.; Cohen, M. L.; Louie, S. G.; Zettl, A. Boron-nitride nanotubes. Science 1995, 269, 966-967.

[15] Zhan, J. H.; Bando, Y.; Hu, J. P.; Golberg, D. Bulk synthesis of single-crystalline magnesium oxide nanotubes. Inorg. Chem. 2004, 43, 2462-2464.

[16] Fan, H. J.; Gosele, U.; Zacharias, M. Formation of nanotubes and hollow nanoparticles based on Kirkendall and diffusion processes: A review. Small 2007, 3, 1660 1671.

[17] Rao, C. N. R.; Nath, M. Inorganic nanotubes. Dalton Trans. 2003, 1-24.

[18] Remskar, M. Inorganic nanotubes. Adv. Mater. 2004, 16, 1497-1504.

[19] Tenne, R. Inorganic nanotubes and fullerene-like nanoparticles. Nat. Nanotechnol. 2006, 1, 103-111.

[20] Rapoport, L.; Bilik, Y.; Feldman, Y.; Homyonfer, M.; Cohen, S. R.; Tenne, R. Hollow nanoparticles of $\mathrm{WS}_{2}$ as potential solid-state lubricants. Nature 1997, 387, $791-$ 793.

[21] Naffakh, M.; Martin, Z.; Fanegas, N.; Marco, C.; Gomez, M. A.; Jimenez, I. Influence of inorganic fullerene-like $W_{2}$ nanoparticies on the thermal behavior of isotactic polypropylene. J. Polym. Sci., Part B: Polym. Phys. 2007, 45, 2309-2321.

[22] Hou, X. H.; Shan, C. X.; Choy, K. L. Microstructures and tribological properties of PEEK-based nanocomposite coatings incorporating inorganic fullerene-like nanoparticles. Surf. Coat. Technol. 2008, 202, 2287 2291.

[23] Parilla, P. A.; Dillon, A. C.; Jones, K. M.; Riker, G.; Schulz, D. L.; Ginley, D. S.; Heben, M. J. The first true inorganic fullerenes? Nature 1999, 397, 114-114.

[24] Golberg, D.; Bando, Y.; Stephan, O.; Kurashima, K. Octahedral boron nitride fullerenes formed by electron 
beam irradiation. Appl. Phys. Lett. 1998, 73, 24412443.

[25] Jose Yacaman, M.; Lopez, H.; Santiago, P.; Galvan, D. H.; Garzon, I. L.; Reyes, A. Studies of $\mathrm{MoS}_{2}$ structures produced by electron irradiation. Appl. Phys. Lett. 1996, 69, 1065-1067.

[26] Remskar, M.; Skraba, Z.; Regula, M.; Ballif, C.; Sanjines, R.; Levy, F. New crystal structures of $W_{2}$ : Microtubes, ribbons, and ropes. Adv. Mater. 1998, 10, 246-249.

[27] Feldman, Y.; Zak, A.; Popovitz-Biro, R.; Tenne, R. New reactor for production of tungsten disulfide hollow onion-like (inorganic fullerene-like) nanoparticles. SolidState Sci. 2000, 2, 663-672.

[28] Margolin, A.; Rosentsveig, R.; Albu-Yaron, A.; PopovitzBiro, R.; Tenne, R. Study of the growth mechanism of $W_{2}$ nanotubes produced by a fluidized bed reactor. J. Mater. Chem. 2004, 14, 617-624.

[29] Zak, A.; Genut, M.; Tenne, R.; Fleischer, N. Insight into the growth mechanism of $W_{2}$ nanotubes in the scaledup fluidized bed reactors. Nano, in press.

[30] Song, X. C.; Zhao, Y.; Zheng, Y. F.; Yang, E. Large-scale synthesis of $\mathrm{MoS}_{2}$ bucky onions. Adv. Eng. Mater. 2007, 9, 96-98.

[31] Yang, H. B.; Liu, S. K.; Lil, J. X.; Li, M. H.; Peng, G.; Zou, G. T. Synthesis of inorganic fullerene-like $W_{2}$ nanoparticles and their lubricating performance. Nanotechnology 2006, 17, 1512-1519.

[32] Albu-Yaron, A.; Arad, T.; Levy, M.; Popovitz-Biro, R.;
Tenne, R.; Gordon, J. M.; Feuermann, D.; Katz, E. A.; Jansen, M.; Muhle, C. Synthesis of fullerene-like $\mathrm{Cs}_{2} \mathrm{O}$ nanoparticles by concentrated sunlight. Adv. Mater. 2006, 18, 2993-2996.

[33] Gordon, J. M.; Katz, E. A.; Feuermann, D.; AlbuYaron, A.; Levy, M.; Tenne, R. Singular $\mathrm{MoS}_{2}, \mathrm{SiO}_{2}$ and Si nanostructures-synthesis by solar ablation. J. Mater. Chem. 2008, 18, 458-462.

[34] Feuermann, D.; Gordon, J. M. High-irradiance reactors with unfolded aplanatic optics. Appl. Opt. 2008, 47, 5722-5727.

[35] Zak, A.; Feldman, Y.; Alperovich, V.; Rosentsveig, R.; Tenne, R. Growth mechanism of $\mathrm{MoS}_{2}$ fullerene-like nanoparticles by gas-phase synthesis. J. Am. Chem. Soc 2000, 122, 11108-11116.

[36] Feldman, Y.; Frey, G. L.; Homyonfer, M.; Lyakhovitskaya, V.; Margulis, L.; Cohen, H.; Hodes, G.; Hutchison, J. L.; Tenne, R. Bulk synthesis of inorganic fullerene-like $\mathrm{MS}_{2}(\mathrm{M}=\mathrm{Mo}, \mathrm{W})$ from the respective trioxides and the reaction mechanism. J. Am. Chem. Soc. 1996, 118, 5362-5367.

[37] Feldman, Y.; Lyakhovitskaya, V.; Tenne, R. Kinetics of nested inorganic fullerene-like nanoparticle formation. $J$. Am. Chem. Soc. 1998, 120, 4176-4183.

[38] Sarin, V. K. Morphological changes occurring during reduction of $\mathrm{WO}_{3}$. J. Mater. Chem. 1975, 10, 593-598.

[39] Hu, J. Q.; Bando, Y.; Zhan, J. H.; Liu, Z. W.; Golberg, D. Uniform and high-quality submicrometer tubes of GaS layered crystals. Appl. Phys. Lett. 2005, 87, 153112. 